\title{
Unsur Semiotik dalam Persembahan Hadrah
}

Utusan Borneo (Sarawak) · 13 Jun 2016 · Oleh Muhammad Zaid Daud

Pendahuluan Persembahan hadrah merupakan satu bentuk hiburan masyarakat awam yang masih mendapat sambutan ramai (walaupun sudah banyak berkurangan atau kurang permintaan). Persembahan hadrah ini masih banyak dipersembahkan di majlis kahwin dan juga di majlis keramaian yang lain. Kebiasaannya, hadrah dipersembahkan semasa mengiringi kehadiran pasangan pengantin. Menurut pandangan peribadi Abang Ali (17 November 2015), tradisi hadrah ini wujud di Tanah Arab terlebih dahulu dan disebarkan di Sarawak oleh para pedagang Arab yang datang berdagang di Sarawak. Ada juga yang menyatakan bahawa hadrah wujud dalam kalangan masyarakat kampung tetapi kesahihannya masih diragui.

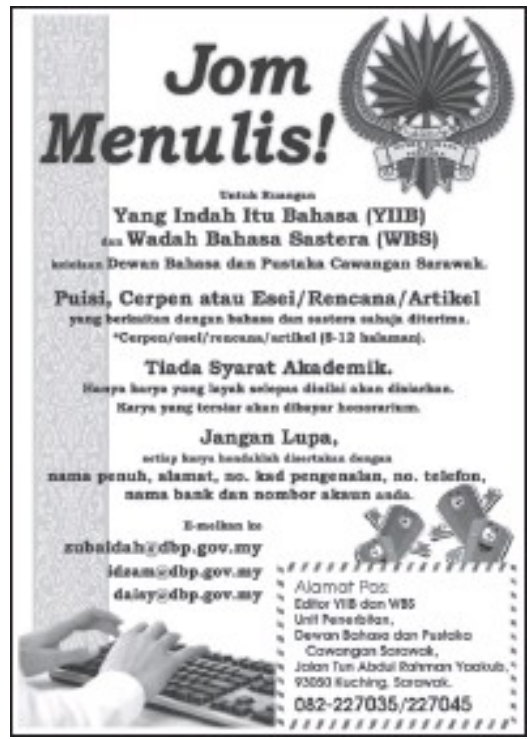

Banyak cerita menarik berkaitan dengan seni hadrah ini, sama ada dalam bentuk kenyataan benar atau pun mitos. Namun semua ini menarik untuk diketahui. Menurut Ahmad Hakimi Khairuddin dan Zahir Ahmad (2006:43), terdapat satu versi persembahan hadrah yang mengatakan bahawa orang-orang yang tersesat di dalam hutan terdengar bunyi pukulan gendang. Kumpulan itu telah pergi ke kawasan bunyi gendang tersebut dan mendapati bahawa bunyi pukulan gendang tersebut datangnya dari sebatang pokok. Mereka telah memotong pokok tersebut untuk mengetahui sebab pokok tersebut mengeluarkan bunyi. Setelah memotong pokok itu, didapati bahawa pokok itu kosong di dalamnya. Oleh sebab itu, mereka mendapat ilham untuk membuat gendang hadrah daripada pokok tersebut dan telah dimainkan di sekitar kampung sebagai satu seni persembahan.

Terdapat juga pendapat yang mengaitkan asalusul persembahan hadrah ini dengan cerita tentang orang sesat di dalam hutan. Untuk menghilangkan rasa bosan mereka telah mengadakan persembahan hadrah di dalam hutan. Permainan gendang tersebut telah didengari oleh golongan raja di kawasan tersebut lalu mereka dijemput untuk mengadakan persembahan di istana (Ahmad Hakimi Khairuddin dan Zahir Ahmad, 2006). Oleh hal yang demikian, terjadilah asimilasi budaya dalam kalangan masyarakat tempatan dan persembahan hadrah tersebut terus dimainkan dan berkembang dalam majlis kahwin, majlis keramaian dan sebagainya. 
Berdasarkan penelitian konsep budaya persembahan hadrah di negeri Sarawak, terdapat perubahan dan pengubahsuaian yang jika dibandingkan dengan persembahan hadrah di Semenanjung Malaysia seperti, cara berpakaian, jenis pukulan gendang, pemilihan lagu, gerak tari dan kumpulan penari yang ramai dalam sesebuah persembahan. Walau bagaimanapun, persembahan hadrah ini mempunyai mesej dalam komunikasi antara masyarakat kerana wujud dalam pelbagai peringkat, mempunyai pelbagai makna, mempunyai beberapa bentuk dan membentuk pelbagai fungsi dalam kalangan masyarakat tempatan.

Keunikan Persembahan Hadrah di Sarawak

Sesebuah kumpulan hadrah akan memiliki beberapa kumpulan kecil di dalamnya. Kumpulankumpulan kecil tersebut diberi nama seperti tingkat, pecah, anak atau anak sungai dan sebagainya. Setiap kumpulan akan mengikut turutan masing-masing seperti tingkat satu, tingkat dua, tingkat tiga dan tingkat empat dan begitu juga dengan kumpulan pecah dan juga kumpulan anak. Anak sungai merupakan variasi bagi kumpulan hadrah lain yang tidak menggunakan istilah anak satu, anak dua dan sebagainya.

Untuk memulakan persembahan hadrah, terdapat beberapa jenis pukulan gendang, dan pukulan yang paling asas adalah pukulan nadi. Pukulan nadi ini merupakan satu pukulan gendang bagi memulakan tradisi hadrah di sesebuah tempat. Sebagai contohnya, ketika kumpulan ini memulakan pukulan kompang atau tar di rumah pengantin lelaki, mereka akan memulakannya dengan pukulan nadi yang lembut dan perlahan. Kemudian mereka akan bertukar ke satu pukulan lain bernama ngakal. Bunyi pukulan ngakal ataupun rentaknya bergantung kepada guru pembimbing kumpulan tersebut kerana setiap kumpulan mempunyai rentak yang berlainan dan unik. Permulaan bagi persembahan hadrah ini semestinya dengan lagu "Bismillah" bagi memohon keberkatan Ilahi dalam melaksanakan sesuatu majlis dengan lancar tanpa sebarang masalah.

Perbezaan antara kompang dan tar ialah kompang merupakan sebuah gendang yang bulat, nipis, dan tidak mempunyai tiga lubang yang melekatkan dua keping logam mana- kala tar mempunyai lubang tersebut. Sehubungan dengan itu, rentak muzik setiap kumpulan berbeza mengikut alat yang mereka gunakan. Setiap kumpulan mempunyai rentak mereka yang tersendiri dan masyarakat dapat mengenali kumpulan hadrah melalui rentak dan alunan bunyi kompang kumpulankumpulan tersebut. Dalam perjalanan dari rumah pengantin lelaki ke rumah pengantin perempuan, kumpulan hadrah tersebut akan mengalunkan selawat supaya mereka selamat sampai ke rumah pengantin perempuan. Apabila majlis persandingan bermula di rumah pengantin perempuan, biasanya kumpulan hadrah akan memulakan lagu persandingan, seperti lagu Sultan Sulaiman, Makkah Madinah dan sebagainya.

Apabila majlis persandingan hampir selesai, akan ada satu pukulan khas bernama tingkahan penutup yang akan dilakukan oleh ketua ataupun guru pembimbing kumpulan hadrah tersebut. Sekiranya kumpulan hadrah sedia untuk memberhentikan persembahan hadrah tersebut, maka lagu yang beralun akan berulang hinggalah guru tersebut membuat tingkahan penutup. Tradisi hadrah ini tidak mempunyai apa-apa unsur ritual kerana menurut masyarakat yang mulamula mengamalkannya, mereka tidak melakukan sebarang pendokumentasian untuk digunakan sebagai rujukan.

Semasa melakukan persembahan hadrah ini, kumpulan tersebut juga boleh menggunakan lagulagu moden untuk dimainkan mengikut rentak tertentu selepas lagu wajib seperti "Bismillah" dan "Sultan Sulaiman" dipersembahkan. Hal ini bertujuan untuk menghiburkan hati para tetamu. Seni 
persembahan hadrah ini diwarisi dari generasi ke generasi bagi memastikannya tetap kekal dan dipraktikkan oleh masyarakat Melayu di Sarawak mahupun di Semenanjung Malaysia.

\section{Unsur Semiotik dan Persembahan Hadrah}

Secara ringkasnya, semiotik mengkaji tandatanda yang mempunyai makna di sekeliling kita serta hubungannya dalam kehidupan kita. Semiotik meliputi tanda atau isyarat verbal serta deria penglihatan, pendengaran, rasa (sentuhan), dan bau.

"Semiotic involves the study not only of what we refer to as 'signs' in everyday speech, but of anything which 'stands for' something else. In a semiotic sense, signs take the form of words, images, sounds, gestures and objects." (Chandler, 2007: 2).

Menurut Johansen dan Larsen (2007: 25) pula, "Signs are phenomena that represent other phenomena".

Dalam persembahan Hadrah, fokus yang diberikan tentang semiotik ialah isyarat yang digunakan oleh guru pembimbing atau ketua kumpulan Hadrah untuk memberikan arahan kepada ahli kumpulan semasa persembahan. Antara isyarat yang digunakan termasuklah; i. Verbal Ketua kumpulan biasanya akan menyanyikan lirik baris pertama atau frasa dalam baris pertama apabila hendak mengulangi sesuatu rangkap. Selain itu, ketua kumpulan juga akan memberikan semangat dengan mengeluarkan bunyi yang pelbagai sebagai galakan kepada ahli kumpulan. Ahli kumpulan pula akan membuat ad-lib (menyanyikan lagu dengan harmoni yang berbeza). ii. Visual Isyarat secara visual merupakan arahan yang paling kerap digunakan oleh ketua kumpulan. Isyarat jenis ini digunakan untuk menandakan penamat lagu dan memperlahankan paluan kompang. Ketua kumpulan Hadrah akan mengangkat kompang selama beberapa saat dan menggerakkan kompang tersebut sekali bagi menandakan penamat lagu yang sedang dipersembahkan.

Ketua kumpulan mengangkat kompang sebagai isyarat untuk berhenti.

Apabila rentak paluan kompang terlalu laju, ketua kompang akan memberikan isyarat menggunakan tangan untuk memperlahankan rentak.

Isyarat yang diberikan oleh ketua kumpulan untuk memperlahankan rentak. iii. Bunyi Isyarat bunyi yang terlibat adalah paluan kom- pang. Menurut responden, setiap ketua kumpulan atau guru pembimbing akan menggunakan rentak sendiri sebagai isyarat kepada ahli kumpulan dan tidak ada rentak khusus bagi tujuan ini. Isyarat ini digunakan bagi menandakan perubahan rentak paluan. Semasa pasangan pengantin sedang menuju ke pelamin, ketua kumpulan akan memulakan paluan kompang dengan rentaknya sendiri dan tingkahan akan bermula. Tingkahan adalah sejenis paluan yang rancak di mana ahli kumpulan akan memainkan rentak yang berbeza.

Kumpulan hadrah mengiringi pasangan pengantin menuju ke pelamin. Kesimpulan Unsur semiotik yang terdapat dalam persembahan hadrah di Sarawak memperlihatkan cirinya yang tersendiri. Kita sedia maklum bahawa persembahan kompang yang mengiringi pengantin berbezabeza mengikut negeri khususnya dalam era moden hari ini. Walau bagaimanapun, persembahan hadrah di Sarawak masih mengekalkan unsur semiotik dalam persembahannya agar seni warisan ini terus terpelihara.

Sungguhpun persembahan hadrah tradisional ada menyelitkan unsurunsur magis yang berasal daripada kepercayaan masyarakat Melayu terdahulu, namun unsur tersebut bertentangan dengan Islam yang merupakan agama utama masyarakat Melayu. Pembaharuan dan penambahbaikan yang dilakukan dalam persembahan hadrah pada masa ini lebih diterima ramai dan tidak bercanggah dengan nilai ajaran Islam. 
Namun begitu, perlu diingat bahawa penam- bahbaikan yang dilakukan memerlukan ilmu pengetahuan yang mencukupi dan difahami bukan sahaja dari sudut agama semata-mata sebaliknya memahami keseluruhan konsep, tujuan dan matlamat persembahan hadrah itu sendiri. Pengubahsuaian ini juga perlulah seiring dengan pelestarian dan pembangunan warisan seni budaya Melayu yang berteraskan ajaran Islam.

Sebagai elemen seni dan budaya, persembahan hadrah ini perlu dikekalkan untuk dipersembahkan dan dipelajari oleh generasi yang akan datang. Kesedaran terhadap peri pentingnya memelihara warisan budaya Melayu perlu diterapkan dalam jiwa generasi muda agar seni dan budaya persembahan hadrah ini tidak lapuk ditelan arus modenisasi global. Hal ini bagi memperlihatkan kepada generasi muda bahawa setiap budaya yang diwarisi mempunyai asal-usul tersendiri yang perlu dikaji dan difahami serta bukan sekadar ikutan "suka-suka" semata-mata. RUJUKAN Ahmad Hakimi Khairuddin dan Zahir Ahmad. (2006). Perkembangan Persembahan Hadrah di Tiga Tempat: Pelestarian dan Pembangunan Warisan Seni Budaya Melayu. Prosiding Persidangan Antarabangsa Pengajian Melayu.

Chandler, D. (2007). Semiotics: The basics (2nded.). (p.2). USA \& Canada: Routledge Taylor and Francis Group.

Johansen, J. D. \& Larsen, S. E. (2007). Signs in Use: An Introduction to Semiotics. (p.25). USA \& Canada: Routledge Taylor and Francis Group. 